\title{
The Impact of the Preparation Season Training Periodization on Motoric and Physiologic Parameters of Elite Male Handball Players
}

\author{
Tufan Dagseven, Tahir Kiliç* \\ 'Department of Sport Sciences, Akdeniz University, Antalya, \\ Turkey
}

Study Area:Antalya, Turkey

Coordinates: $29^{\circ} 35^{\prime} \mathrm{N} ; 36^{\circ} 29^{\prime} \mathrm{E}$

Keywords: Fitness, Practice season

\section{Introduction:}

Handball is a competitive team sport that demands full participation with physical, technical, mental, and tactical abilities. Considering team tactics and performance required in handball, athletes have extraordinary physical abilities individually and as a team to achieve success. Handball is a very dynamic sport discipline. Short actions no more than 10-20 seconds during the competition require high-intensity repetition. Anaerobic energy systems support approximately $30-35 \%$ of the playing time. Techniques (fakes, jumps, multi-direction sprints, etc.) and tactical behaviors (dribbling, individual defensive moves, direct contact with the opponent, etc.) used during the competition require the players to maintain a highperformance level. The extent of competition depends on the performance level, applied technique, and tactics (Gorostiaga et al., 2006; Povoas et al., 2012; Wagner et al., 2017; Ilkim et al., 2018). Contemporary education theory was developed in the early 1960 s by Matveyev (1964) and Ozolin (1970). This theory was later referred to as the conventional or traditional periodization training model in the 1970s. The frequent and high-intensity workloads are reduced with the beginning of the competition period as

\section{Abstract}

The combined training method and the conventional preparation training method are the most important phase of the workload covering a season. In the present study, during the 8-week preparation period, the preparation period training, a combined training 8-10 times in 6 days a week, was applied to the experimental group. The control group performed a conventional preparation period training for 4 days and 6 times per week. The findings indicate that statistical significances in the pretest and posttest values of the $30-\mathrm{m}$ sprint, There were statistically significant differences in the Cooper test and left-hand claw strength values by the conventional preparation training method. The heart rate variable showed statistical significance as the maximum heart rate, and anaerobic threshold values from the group performed the conventional preparation training method. A statistical significance was discovered in aerobic threshold capacity values from the group performed the combined training method. Although there were differences in body composition measurements and flexibility values, they were not statistically significant.

their performances improve (Carmen et al., 2017; Issurin, 2008). Considering the workload covering a season in handball, the most crucial phase of the annual training period is the preparation period for performance maximization, injury prevention, and completing physical and mental preparations. Athletes are expected to be physically and mentally prepare themselves during the preparation period for the competition period, an intense and comprehensive period. The aim is to develop motoric properties such as general strength, endurance, maximum strength, speed, and quickness at the beginning of the preparation period. The training progress from the general and continue as branch-specific exercises. The load scopes are broad with low intensity. As the competition period approaches, the scope is specified, and the intensity is increased (Sevim, 1996). Contemporary scholarship on the physical and physiological images of athletes is in a development trend (Bilge et al., 200o). Productive results of well-planned loads necessitate thorough planning towards the intensity, frequency, and density. Several studies reported that training loads with shorter duration and high intensity are more effective (Fox et al., 1988). Change and development have become an integral part of team sports.

*Corresponding Author: tkilic@akdeniz.edu.tr 
Thanks to the scientific development and improvements for the tools, studies are better conducted with scientific principles. It was observed that more efficient training plans and programs could be prepared through the evaluation of the results (Sevim, 1996). This research aims to compare the Men's Handball Super League team of Antalyaspor handball team and the 2018-2019-year universities Turkey indoor and beach handball champions Akdeniz University Men's Handball Team preparation period training in 2018-19. The combined training method was applied to the Antalyaspor Handball Team for 8 weeks in the preparation period training, while the conventional load training method was applied to the Akdeniz University men's handball team during the preparation period. Preparation period training sessions are planned as 8 weeks in a single period. Both team players are top elite male handball players. The study presents a comparative analysis of two different training methods applied in the preparation period..

\section{Materials and methods:}

The experimental group participants were given training for 6-8-10 days a week, double training in a day as the stages progress, (120 minutes/day) prepared by the combined training method. The control group performed a conventional preparation period training for 3 days and 5 times (120 minutes/day) per week.

Training program content: it includes physical preparations through the combined training method to improve aerobic and anaerobic capacity, strength, mobility, endurance, motoric properties such as speed, and quickness, recovery speed, and decrease the body fat percentage. Control group training content included physical preparations with a conventional training method including pyramidal strength, sub-maximal, maximal, quick strength, aerobic and anaerobic endurance, cross, speed, and quickness training. All athletes participating in the study were tested before the preparatory period and at the beginning of the competition period (at the end of 8 weeks). The study covers 8-weeks in total, including initiation, outcome measurements, and preparation period training.

Population and sample: Antalyaspor men's handball team competed in the 2018-2019 Super League n16 comprised the experimental group and the Akdeniz University men's handball team n16 from the Interuniversity 1st League is included in the control group.

Data Collection Tools: Cooper Test, digital heart rate measurements (resting heart rate, maximum heart rate, $\left.\mathrm{VO}_{2} \mathrm{Max}\right)$, 30-m sprint test, hand claw strength measurement, leg and back strength measurement, flexibility test (sit and reach), body composition measurements, weight and height measurements. The heart rate of the participants was determined with the digital heart rate measurement tool and Polar Precision Performance Software computer package program. Based on these measurements, the maximum oxygen consumption capacity, maximum heartbeat, resting heart rate, aerobic threshold, and anaerobic threshold data was predicted by the program. These data were used to monitor the instantaneous status of the athletes during heavy load training protocols. Statistical research results were calculated by using the IBM statistics data editor package program.

\section{Results :}

The preparation period training in the study including the physical, mental, emotional and psychological preparation of the athletes for intense loading, the application of the conventional high loading principle and the combined training method, the adaptation and concentration to the high load, the physiological and psychological renewal processes of adapting to the competition were applied. The measurements applied to the experimental and control groups before and after the preparation period are presented below.

Table-1:Heart rate measurements of sample groups $(\mathrm{n}=16)$

\begin{tabular}{llll}
\hline Variables & Group & Avg. \pm Sd & $\mathrm{P}$ \\
\hline Maximum oxygen consumption & Exp. & $51.00 \pm 2.00$ & 0.959 \\
capacity $(\mathrm{ml} / \mathrm{kg} / \mathrm{min})$ & Con. & $50.93 \pm 4.37$ & \\
Maximum heart rate (beats $/ \mathrm{min})$ & Exp. & $191.68 \pm 3.52$ & $0.000^{* \mathrm{~b}}$ \\
& Con. & $199.00 \pm 2.73$ & \\
Resting heart rate (beats $/ \mathrm{min})$ & Exp. & $65.62 \pm 4.80$ & 0.970 \\
& Con. & $65.68 \pm 4.48$ & \\
Aerobic threshold (beats $/ \mathrm{min})$ & Exp. & $143.50 \pm 2.58$ & $0.000^{* \mathrm{a}}$ \\
& Con. & $149.25 \pm 1.98$ & \\
Anaerobic threshold (beats $/ \mathrm{min})$ & Exp. & $174.93 \pm 7.08 \quad 0.036^{* \mathrm{~b}}$ \\
& Con. & $179.06 \pm 2.49$ \\
\hline
\end{tabular}

There was a statistically significant difference between the aerobic and anaerobic threshold values and the maximal oxygen consumption capacity between the groups. The difference between the maximum heartbeat and anaerobic threshold values is in favour of the control group, while the difference in aerobic threshold values is in favour of the experimental group. These differences between the groups are thought to be due to the age differences of the athletes.

No statistical significance was found between the flexibility test values from the experimental and control groups. It was observed that there was a statistically significant difference in the experimental group 30-m sprint pretest and post-test averages. It was observed that there was a statistically significant difference between Cooper test pretest and post-test averages. There was a statistically significant difference in favour of the control group in the Cooper test (pretest) comparisons, while no statistically significant difference was found when the posttest averages of the groups were compared. 
TECHNOSCIENCE ARTICLE

Table-2: Experimental and control group. flexibility. 30-m sprint test. cooper test measurements

\begin{tabular}{|c|c|c|c|c|}
\hline $\begin{array}{l}\text { Variables } \\
\text { Group }\end{array}$ & Protocol (test) & $\mathrm{N}$ & Mean \pm Sd & $\mathrm{P}$ \\
\hline \multicolumn{5}{|c|}{ Flexibility $(\mathrm{cm})$} \\
\hline \multirow[t]{2}{*}{ Exp. } & Pre & 16 & $30.69 \pm 6.19$ & 0.189 \\
\hline & Post & 16 & $32.53 \pm 6.51$ & \\
\hline \multirow[t]{4}{*}{ Con. } & Pre & 16 & $30.26 \pm 10.08$ & 0.888 \\
\hline & Post & 16 & $32.28 \pm 6.3$ & \\
\hline & Pre-Pre & 32 & & 0.890 \\
\hline & Post-Post & 32 & & 0.913 \\
\hline \multicolumn{5}{|c|}{30 m Sprint Test (sec.) } \\
\hline \multirow[t]{2}{*}{ Exp. } & Pre & 16 & $4.58 \pm 0.24$ & $0.003^{*}$ \\
\hline & Post & 16 & $4.43 \pm 0.17$ & \\
\hline \multirow[t]{4}{*}{ Control } & Pre & 16 & $4 \cdot 37 \pm 0.2$ & 0.140 \\
\hline & Post & 16 & $4 \cdot 30 \pm 0.17$ & \\
\hline & Pre-Pre & 32 & & 0.140 \\
\hline & Post-Post & 32 & & $0.043^{* \mathrm{a}}$ \\
\hline \multicolumn{5}{|c|}{ Cooper Test (m.) } \\
\hline \multirow[t]{2}{*}{ Exp. } & Pre & 16 & $2612.5 \pm 192.79$ & $0.018^{*}$ \\
\hline & Post & 16 & $2687 \cdot 5 \pm 170.78$ & \\
\hline \multirow[t]{4}{*}{ Control } & Pre & 16 & $2262.5 \pm 250$ & $0.000^{*}$ \\
\hline & Post & 16 & $2593.75 \pm 335 \cdot 59$ & \\
\hline & Pre-Pre & 32 & & $0.000^{*^{b}}$ \\
\hline & Post-Post & 32 & & 0.327 \\
\hline
\end{tabular}

Table-3: Force test measurements of sample groups

\begin{tabular}{|c|c|c|c|c|}
\hline $\begin{array}{c}\text { Variables } \\
\text { Group } \\
\end{array}$ & Protocol (test) & $\mathrm{N}$ & Mean \pm Sd & $\mathrm{P}$ \\
\hline \multicolumn{5}{|c|}{ Leg Force (kg.) } \\
\hline \multirow[t]{2}{*}{ Exp. } & pre & 16 & $127.11 \pm 19.72$ & 0.572 \\
\hline & post & 16 & $129.39 \pm 16.45$ & \\
\hline \multirow[t]{4}{*}{ Con. } & pre & 16 & $137.75 \pm 11.79$ & 0.305 \\
\hline & post & 16 & $141.89 \pm 17.48$ & \\
\hline & pre-pre & 32 & & $0.048^{* \mathrm{~b}}$ \\
\hline & post-post & 32 & & $0.053^{*^{b}}$ \\
\hline \multicolumn{5}{|c|}{ Back Force (Kg.) } \\
\hline \multirow[t]{2}{*}{ Exp. } & pre & 16 & $133.81 \pm 18.84$ & 0.194 \\
\hline & post & 16 & $139.16 \pm 16.92$ & \\
\hline \multirow[t]{4}{*}{ Con. } & pre & 16 & $139 \cdot 56 \pm 12.61$ & 0.490 \\
\hline & post & 16 & $145.62 \pm 13.37$ & \\
\hline & pre-pre & 32 & & 0.346 \\
\hline & post-post & 32 & & 0.270 \\
\hline \multicolumn{5}{|c|}{ Right-hand claw force (Kg.) } \\
\hline \multirow[t]{2}{*}{ Exp. } & pre & 16 & $51 \pm 6.54$ & $0.045^{\star^{a}}$ \\
\hline & post & 16 & $53.13 \pm 6.01$ & \\
\hline \multirow[t]{4}{*}{ Con. } & pre & 16 & $48.2 \pm 7.56$ & 0.679 \\
\hline & post & 16 & $48.70 \pm 6.70$ & \\
\hline & pre-pre & 32 & & 0.276 \\
\hline & post-post & 32 & & 0.096 \\
\hline \multicolumn{5}{|c|}{ Left-hand claw force (Kg.) } \\
\hline \multirow[t]{2}{*}{ Exp. } & pre & 16 & $51 \cdot 31 \pm 5 \cdot 33$ & 0.598 \\
\hline & post & 16 & $52.06 \pm 5.16$ & \\
\hline \multirow[t]{4}{*}{ Con. } & pre & 16 & $46.47 \pm 7.83$ & 0.158 \\
\hline & post & 16 & $48.31 \pm 8.86$ & \\
\hline & pre-pre & 32 & & 0.860 \\
\hline & post-post & 32 & & 0.164 \\
\hline
\end{tabular}

There was no statistically significant difference in leg strength, back strength, right-hand claw strength, and lefthand claw strength values. A statistically significant difference was observed in favour of the control group in terms of leg strength (posttest) values and in favour of the experimental group in terms of right-hand claw strength (posttest) values.

Table-4: Body composition measurements of sample groups

\begin{tabular}{|c|c|c|c|c|}
\hline $\begin{array}{l}\text { Variables } \\
\text { Group } \\
\end{array}$ & Protocol (test) & $\mathrm{N}$ & Mean \pm Sd & $\mathrm{P}$ \\
\hline \multicolumn{5}{|c|}{ Body Fat Percentage (\%) } \\
\hline \multirow[t]{2}{*}{ Exp. } & Pre & 16 & $16.49 \pm 3.75$ & 0.196 \\
\hline & Post & 16 & $16.71 \pm 3.82$ & \\
\hline \multirow[t]{4}{*}{ Con. } & Pre & 16 & $16.20 \pm 4.97$ & 0.855 \\
\hline & Post & 16 & $16.66 \pm 5.83$ & \\
\hline & Pre-Pre & 32 & & 0.873 \\
\hline & Post-Post & 32 & & 0.984 \\
\hline \multicolumn{5}{|c|}{ Fat Mass (Kg.) } \\
\hline \multirow[t]{2}{*}{ Exp. } & Pre & 16 & $15.41 \pm 4.90$ & 0.318 \\
\hline & Post & 16 & $15.61 \pm 4.89$ & \\
\hline \multirow[t]{4}{*}{ Con. } & Pre & 16 & $15.08 \pm 7.00$ & 0.324 \\
\hline & Post & 16 & $15.78 \pm 8.75$ & \\
\hline & Pre-Pre & 32 & & 0.334 \\
\hline & Post-Post & 32 & & 0.950 \\
\hline \multicolumn{5}{|c|}{ Muscle Mass (Kg.) } \\
\hline \multirow[t]{2}{*}{ Exp. } & Pre & 16 & $70.94 \pm 7.61$ & 0.481 \\
\hline & Post & 16 & $70.76 \pm 7.70$ & \\
\hline \multirow[t]{4}{*}{ Con. } & Pre & 16 & $69 \cdot 32 \pm 9.53$ & 0.679 \\
\hline & Post & 16 & $69.49 \pm 10.17$ & \\
\hline & Pre-Pre & 32 & & 0.593 \\
\hline & Post-Post & 32 & & 0.669 \\
\hline \multicolumn{5}{|l|}{ Weight (kg) } \\
\hline \multirow[t]{2}{*}{ Exp. } & Pre & 16 & $91.64 \pm 12.26$ & 0.598 \\
\hline & Post & 16 & $91.53 \pm 12.33$ & \\
\hline \multirow[t]{4}{*}{ Control } & Pre & 16 & $87.80 \pm 17.02$ & 0.158 \\
\hline & Post & 16 & $88.19 \pm 19.16$ & \\
\hline & Pre-Pre & 32 & & 0.497 \\
\hline & Post-Post & 32 & & 0.576 \\
\hline
\end{tabular}

No statistical significance was observed regarding the experimental and control groupvariables.

Discussion and Conclusion:

Results of several scholars such as Sentürk (2016), Hermassi et al., (2014), Zorba et al., (2014), Nikolaidis et al., (2016), Koç (2010), Wagner et al., (2017), Po'voas et al., (2012), Sporis et al., (2010) Sýnýrkavak et al., (2004), Eler \& Eler (2018) and the scholarship confirm the generalizability level of the results. The experimental group averaged a maximum oxygen consumption capacity of $51.00 \pm 2.00$, as the maximum heart rate average was $191.69 \pm 3.52$, with a resting heart rate average of $65.63 \pm 4.80$, aerobic threshold average of $143.50 \pm 16.00$, and mean anaerobic threshold was measured as $174.94 \pm 7.08$. The Control group maximum oxygen consumption capacity average was 50.94 \pm 4.37 with a maximum heart rate average of $199.00 \pm 2.73$, resting heart rate average of $65.69 \pm 4.48$, aerobic threshold average of 
$149.25 \pm 1.98$ as the anaerobic threshold average was calculated as $179.06 \pm 2.49$. The study results coincide with contemporary scholarship and relevant findings (Cselkó et al., 2013; Wagner et al., 2017; Po'voas et al., 2012; Sporis et al., 2010; Sýnýrkavak et al., 2004). No statistical significance was found between the pretest and post-tests of the flexibility test values from the experimental and control groups. It was observed that there was a statistically significant difference in the experimental group 30-m sprint pretest and posttest averages. The 30-m sprint test and pretest averages of the experimental and control groups revealed no statistically significant differences. However, it was observed that there was a statistically significant difference in favor of the experimental group in the 30-m sprint posttest scores. It was observed that there was a statistically significant difference between the experimental and control groups' Cooper test pretest and posttest averages. There was a statistically significant difference in favour of the experimental group in the Cooper test pretest results, while no statistically significant difference was found after the post-tests. The study results coincide with contemporary scholarship with close average values and similarities (Atepoðlu et al., 2011; Koç \& Aslan, 2010; Kilinç \& Özer, 2011; Aktuð 2013; Zorba et al., 2014; Arabaci et al., 2007; Chaouachi et al., 2009; Massuca et al., 2015; Koç et al., 2011; Wagner et al., 2017; Zorba et al., 2014; Alp et al., 2015; Eler et al., 1999). There was no statistically significant difference between the pretest and post-test averages of the strength test values of the experimental group in terms of leg, back, left-hand claw strength values. Moreover, there was a significant difference in right-hand claw strength values in favour of the experimental group and the leg strength in favor of the control group. The study results coincide with contemporary scholarship with close average values and similarities (Zorba et al., 2014; Ýri et al., 2003; Senel \& Göral 2014; Alp et al., 2015; Eler et al., 1999). The study revealed no statistically significant differences between the pretest-posttest body composition averages of the experimental and control groups while the fat percentage, fat mass, muscle mass, and weight variables proved significant differences. The study results coincide with contemporary scholarship with close average values and similarities (Cselkó et al., 2013; Povóas et al., 2012; Sporis et al., 2010; Sýnýrkavak et al., 2004; Eler et al., 1999).

The results show that several physical fitness parameters for handball players are correlated and their average values regarding strength, sprint speed, heart rate, body composition, and flexibility characteristics are substantially good in comparison to contemporary scholarship. The research results revealed that starting the preparation period with a conventional training method and applying the combined training method towards the end of this period should more beneficial for the development of the athletes. It was observed that the 8- week preparation period training is not sufficient to maintain the athletes' physical fitness level in the competition period. The results indicate that the 8-week preparation period is not sufficient considering the process in a complete season. Considering factors such as the transfer movements in the pre-season, the disruptions in the initial planning of the season, social and economic problems, and the stress caused by the intensive training at the season-opening, more thorough planning for further studies and athletes should be protected from the negative circumstances in the pre-season. Furthermore, it is thought that dominant hand and leg preferences should be taken into consideration for strength measurements, and psychosocial data such as the readiness, satisfaction, and anxiety levels of the athletes should be included in the preseason studies.

\section{References:}

Aktug, B.Z. (2013): Isokinetic hamstring and quadriceps muscle strength ratio with vertical jump and speed performance correlation in football players. Selçuk University Health Sciences Institute. MA Thesis, Konya.

Alp, M., Kilinç, F. \& Suna, G. (2015): Investigating the Training' Effects Applied to Hand-Ball Players in Preparation Season on Some Anthropo-Metric and Biomotoric Features. Int. Refer. Acad. J. Sports, Health Med. Sci., 17:47-59.

Arabaci, R., Erol, S. \& Gültekin, O. (2007): The research on physical performance of male handball players who played in super league. Sport Sci., 2(4):62-70.

Bilge, M. (2007): An Investigation of the Relationship Between Peak Anaerobic Power-Capacity, Body Composition and Heart Rate in Turkish National Senior Handball Players. Gazi University Health Sciences Institute. Ph.D. Dissertation, Ankara.

Bilge, M., Müniroglu, S. \& Gündüz, N, (200o): Somatotype profiles of Turkish female handball national team players and comparison with foreign country athletes. J. Sport. Stud., 4(1):33-44.

Carmen, M., Juan, M., Cortell, T. \& Juan, T.M. (2017): Effects of two different training periodization models on physical and physiological aspects of elite female team handball players. $L$ Streng. Condition. Res., 32(1):280-287.

Chaouachi, A., Brughelli, M., Levin, G., Boudhina, N.B., Cronin, J. \& Chamari, K. (2009): Anthropometric, physiological and performance characteristic of elite team-handball players. I. Sport. Sci., 15;27(2):151-7.

Cselkó, A., László, Z., Tékus, E. \& Wilhelm, M. (2013): Anthropometric and cardiovascular characteristics of young elite male handball players according to playing positions. Exer. Qual. Life, 5(1):31-41.

Eler, N. \& Eler, S. (2018): 2D: 4 D, lateralization and strength in handball players. L. Edu. Train. Stud., 6(5).

Eler, S., Yildiran, I. \& Sevim, Y. (1999): The examination of some motoric and physiological parameters of elite class handball players throughout one season training period. Gazi J. Phy. Edu. Sport. Sci.,4(3):25-34.

Fox, E.L., Bowers, R.W. \& Foss, L.M. (1988): The Physiological Basis of 


\section{TECHNOSCIENCE ARTICLE}

Physical Education and Athletics. Pub by: Sounders College Publishing, :62-82, 675 .

Golding, L.A., Myers, C.R. \& Sinning, W.E. (1982): The Y's Way to Physical Fitness. Pub. by: Human Kinetics, Rosemont. 191 P.

Gorostiaga, E.M., Granados, C., Ibanez, J., Gonzalez-Badillo, J.J. \& Izquierdo, M. (2006): Effects of an entire season on physical fitness changes in elite male handball players. Med. Sci. Sports Exer. 38:357-366.

Hermassi, S., Gabbett, T., Ingebrigtsen, J. \& Tilliar, R.V.D. (2014): Effects of a short-term in-season plyometric training program on repeated sprint ability, leg power and jump performance of elite handball players. Int. J. Sports Sci. Coach., 9(5):1205-1216.

Ilkim, M., Canpolat, B. \& Akyol, B. (2018): The effects of eight-week regular training in amateur amputee football team athletes' body composition. Tur. J. Sport Exerc., 20(3):199-206.

Iri, R., Baslamisl, A. \& Göksu, Ö.C. (2003): 18-21 The analysis of the physical and motor characteristics features of the speedy power exercised applied to the preparation period to male handball players of 18-21 age range. Res. Sport Sci., 11(3):47-52.

Issurin, V. (2008): Block periodization versus traditional training theory: A review. J. Sport. Med. Phys. Fitness, 8:65-75.

Kilinç, F. \& Özer, Ö. (2011): Elite athletes in individual and team strength, speed and flexibility to compare their performance. Int. J. Human Sci.,9(1):360-371.

Koç, H. (2010): Combined training program effects on aerobic and anaerobic capacities in male handball players. Tur. Kick Boxing Federat. J. Sport Sci., 3(2):48-56.

Koç, H, Pulur, A, Karabulut, E . (2011). Comparison of Some Motor Abilities of Male Basketball and Handball Players. J. Phy. Edu. Sport. Sci. Niğde Univer., 5(1):21-27

Massuca, L., Branco, B., Miarka, B. \& Fragoso, I. (2015): Physical fitness attributes of team-handball players are related to playing position and performance level. Asian J. Sport. Med., 6(1):e24712.

Matveyev, L.P. (1964): Problem of Periodization the Sport Training. Pub. by: Fizkultura I Sport. Moscow, Russia.
Ambient Science, 2021: Vol. 08(Sp1); 19-23 DOI:10.21276/ambi.2021.08.sp1.ta03

Nikolaidis, P.T., Luque, G.T., Chtourou, H., Suarez, V.J.C., Velez, R.R. \& Heller, J. (2016): Comparison between jumping vs. cycling test of short-term power in elite male handball players: the effect of age. Movem. Sport Sci., 91(1):93.

Özer, K. (2001): Physical Fitness. Pub. by: Nobel Press, Ankara.

Ozolin, N.D. (1970): The Modern System of Sport Training. Pub. by: Fizkultura I Moscow, Russia Sport.

Po'voas, S.C.A., Seabra, A.F.T., Ascensa o, A.A.M.R., Magalha es, J., Soares, J.M.C. \& Rebelo, A.N.C. (2012): Physical and physiological demands of elite team handball. J. Streng. Cond. Res., 26(12):3365-3375.

Senel, E. \& Göral, K. (2014): The comparison of Turkish folk dancers with sedentary people in terms of some physical fitness parameters. Int. J. Sci. Cult. Sport, 2(1):19-26.

Sentürk, I. (2016): Examination of Speed, Agility and Strength Parameters of Elite Handball Players by Their Position. MA Thesis. Marmara University Health Sciences Institute, Istanbul.

Sevim, M, Sevim, Y, Günay, M , Erol, E . (1996): Effects of combined strength training on Elite Female Handball Players aged 18-25 years. Gazi Univer. J. Phy. Edu. Sport. Sci., 1(3):1-10

Sinirkavak, G., Dal, U. \& Çetinkaya, Ö. (2004): The relation between the body composition and maximal oxygen capacity in elite sportsmen. C. Ü. Med. Facul. J., 26(4):171-176.

Sporis, G., Vuleta, D., Vuleta, D.J. \& Milanoviç, D, (2010): fitness profiling in handball: Physical and physiological characteristics of elite Players. Coll. Antropol.,34(3):1009-1014.

Tamer, K. (2000). Measurement and Evaluation of Physical-physiological Performance in Sports. Pub. by: Bagirgan Publishing, Ankara.

Wagner, H., Gierlinger, M., Adzamija, N., Ajayi, S., Bacharach, D.W. \& von Duvillard, S.P. (2017): Specific physical training in elite male team handball. J. Streng. Cond. Res., 31(11):3083-3093.

Zorba, E., Göral, K. \& Göral, S. (2014): Examining relationships between some physical fitness parameters of elite handball players. Int. Conf. Sci. Cult. Sport, :192. 